Fourth International Conference on Sustainable Construction Materials and Technologies http://www.claisse.info/Proceedings.htm

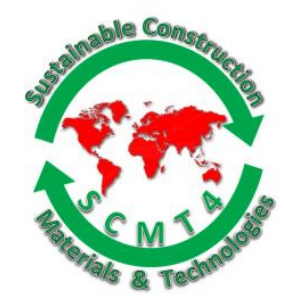

SCMT4

Las Vegas, USA, August 7-11, 2016

\title{
Creep of Concrete with High Amounts of Supplementary Cementitious Materials and Applications in Concrete-Filled Tubes
}

\author{
Katie Kuder', Dawn Lehman ${ }^{2 a}$, Jie Chien ${ }^{3}$, Charles Roeder ${ }^{2 b}$ and Laura Lowes $^{2 \mathrm{c}}$ \\ ${ }^{1} 90112^{\text {th }}$ Ave; Seattle, WA 98122-1090, Civil and Environmental Engineering; Seattle University, \\ Email: <kuderk@seattleu.edu>. \\ ${ }^{2}$ More Hall; Seattle, WA 98195-2700, Civil and Environmental Engineering; University of Washington, \\ ${ }^{2 a}$ Email: <delehman@uw.edu>, ${ }^{2 b}$ Email: < croeder@uw.edu >, ${ }^{2 c}$ Email: <lowes@uw.edu>. \\ ${ }^{3}$ Key Lab of Structures Dynamic Behavior and Control of the Ministry of Education (Harbin Institute of \\ Technology), Harbin, 150090, China, Email :<chenjiehit@163.com>.
}

\begin{abstract}
Due to its design versatility, availability and cost efficiency, concrete continues to play a dominant role in the construction industry. However, the production of Portland cement, a primary component of typical concrete mixes, is known to have a serious impact on the environment. Increasing the use of supplementary cementitious materials (SCMs) in concrete is an obvious and necessary step to reduce the carbon emissions associated with cement production. However, most reinforced concrete (including cast-in-place and precast) structural components rely on the early stiffness and strength of the concrete to resist self-weight and construction loadings after the release of the formwork. In contrast to cement-only concretes, high SCM concretes require more time to reach the target strength and stiffness values. Therefore, a structural component that does not depend on these engineering properties during construction is preferred. Concretefilled tubes (CFTs) offer a solution to this challenge, with the steel tube is able to support construction loads while the high SCM concrete fill develops its strength and stiffness. However, there are concerns about the long-term deformations (creep) of high SCM concrete and its impact on CFT performance. This research develops models to predict the long-term (creep) response of SCM concretes and uses those predictive models to assess the long-term response of CFTs with SCM concrete fill. The models were validated using a large SCM database and two full-scale CFTs with SCM concrete fill that were tested under sustained loading.
\end{abstract}

\section{INTRODUCTION}

For every ton of cement produced, approximately a ton of $\mathrm{CO}_{2}$ is emitted. According to the European Cement Association, cement production in 2013 increased 9.4\% to 4.0 billion tons from 2012 (Cembureau 2013). Thus, the carbon footprint associated with cement production is high.

Increasing the use of supplementary cementitious materials (SCMs) in concrete is an obvious and necessary step to reduce carbon emissions (Mehta 2009). SCMs, such as silica fume, fly ash and slag, are often waste materials from industrial processes. These by-products possess hydraulic and/or pozzolanic properties and, 
when used at optimal levels, enhance fresh state properties, mechanical performance and composite durability. Inclusion of SCMs in cement-based composites lessens the environmental impact in several ways, in that it: (1) reduces Portland cement consumption and thereby production, (2) can reduce the amount of inert filler (typically sand in conventional concrete) required and (3) uses waste materials that would otherwise be land filled.

Because of their elongated cure time, SCM concretes cannot be used in all structural applications. One structural application that minimizes structural performance uncertainties that are associated with the longer time required to reach the target strength and modulus values of SCM concretes are concrete-filled tubes (CFTs) (Lehman et al. 2015). CFTs are composite members consisting of a steel tube with concrete infill. The exterior steel tube serves as formwork, reinforcing and confining steel to the concrete fill. The fill restrains local buckling of the steel tube. CFTs have high strength-to-size efficiency compared to conventional reinforced concrete members due to the optimal location of the steel. In addition to their strength and stiffness, CFTs permit rapid construction. CFTs are typically used for columns in high-rise buildings, bridge piers, and deep foundations (Lehman et al. 2015; Roeder et al. 2010; Lehman \& Roeder 2012; Moon et al. 2013).

Previous experiments show that CFTs using concretes with cement-replacement SCM concrete fill with fly ash and slag replacement levels up to $80 \%$ do not compromise structural performance, because the steel tube supports the initial construction and other loads that are present while the SCM concrete gains its longterm strength and stiffness (Lehman et al. 2015). In comparison to RC members, CFTs are less dependent on high early concrete strength and modulus of elasticity due to the presence of the steel tube, and concrete hydration and strength development are likely enhanced due to reduced moisture loss within the sealed tube (Kuder et al. 2012; Hannesson et al. 2012).

However, lower initial strength and stiffness in the SCM concrete fill may increase the stress and deformation of the steel tube in a CFT system. Geng et al. noted that loads that are applied at early concrete age could induce significant long-term deformation, especially for the composite columns with large diameter-to-thickness ratio (e.g. $\mathrm{D} / \mathrm{t}=100)(\mathrm{Geng}$ et al. 2012). Other research by the authors shows that the likelihood of yielding and buckling of the steel tube was limited, but a model to predict the long-term performance of SCM concrete was needed to verify this finding for a wider range of design parameters (Lehman et al. 2015).

Creep is the time-dependent deformation of concrete under compressive load. It is comprised of two parts: (1) basic creep and (2) drying creep. Creep is often responsible for excessive deflection or cracking at service loads and its effect on structural behavior have been actively researched (Holger et al. 2012; Castel et al. n.d.; Wang et al. n.d.). The slower development of stiffness and strength in high SCM concrete increases concern of the impact of creep and adds a complexity for which the time-dependent modulus variation must be accounted.

Prior studies have evaluated the creep of SCM concrete experimentally. Research has shown that SCMs can have a significant effect on the time-dependent deformation of concrete (Bazant \& Baweja 2000; Kuder et al. 2012). Prior tests have examined control concrete mixes, binary mixes (fly ash and cement (Hannesson et al. 2012; Lohtia et al. 1976; Ghosh \& Timusk 1981; Nasser \& AI-Manaseer 1986; Langley et al. 1989; Sivasundaram et al. 1991; Carette et al. 1993) or slag and cement (Hannesson et al. 2012; Chern \& Chan 1989; Li 2001) and ternary mixes (fly ash, slag and cement (Kuder et al. 2012)). Researchers have also studied SCM replacement levels; typical replacement percentages range between 0 and $60 \%$ (Hannesson et al. 2012; Lohtia et al. 1976; Ghosh \& Timusk 1981; Nasser 1987; Langley et al. 1989; Sivasundaram et al. 1991; Carette et al. 1993; Chern \& Chan 1989; Li 2001); very few exceed 60\%, including one by the authors (Hannesson et al. 2012; Carette et al. 1993; Li 2001). In addition, the effect of the water-to-binder ratio 
(Lohtia et al. 1976; Ghosh \& Timusk 1981; Sivasundaram et al. 1991), age at first loading (Sivasundaram et al. 1991; Carette et al. 1993; Chern \& Chan 1989; Li 2001) and the initial stress level (Nasser \& AIManaseer 1986; Kuder et al. 2012) have been considered. These results reported in the literature are used to develop and validate the creep models developed herein.

This research investigates creep in concrete mixes with high volumes of fly ash and slag, develops accurate models for time-dependent engineering properties of SCM concretes and uses the resulting creep model to study the impact of using SCM concretes in CFTs under sustained loading. To develop a comprehensive CFT creep model that accounts for all of the time-dependent aspects of SCM concretes, additional expressions are needed for the time-dependent development of the compressive strength and modulus of elasticity. These expressions are used to model creep behavior.

\section{BASIC LONG-TERM PROPERTIES FOR SCM CONCRETE}

For concrete under service-level loading with compressive stress demands less than approximately $45 \%$ of the concrete compressive strength, $\mathrm{f}_{\mathrm{cm}}$, creep and instantaneous strains are proportional to stress and may be computed from the creep coefficient and creep function as follows using the following equation from the European standard EN 1992-1-1 (EC2) (European Committee for Standardization (CEN) EN 1992):

$$
\begin{aligned}
& \varepsilon_{\mathrm{e}}\left(t_{0}\right)+\varepsilon_{\mathrm{cr}}\left(t_{\mathrm{k}}, t_{0}\right)=J\left(t_{\mathrm{k}}, t_{0}\right) \sigma_{\mathrm{c}}\left(t_{0}\right) \\
& J\left(t_{\mathrm{k}}, t_{0}\right)=\frac{1}{E_{\mathrm{c}}\left(t_{0}\right)}\left(1+\varphi\left(t_{\mathrm{k}}, t_{0}\right)\right) \\
& \varphi\left(t_{\mathrm{k}}, t_{0}\right)=\frac{\varepsilon_{\mathrm{cr}}\left(t_{\mathrm{k}}, t_{0}\right)}{\varepsilon_{\mathrm{e}}\left(t_{0}\right)}
\end{aligned}
$$

where $t_{k}$ is the time from casting of the concrete (days); $t_{0}$ is the time at initial loading (days); $\varepsilon_{c r}\left(t_{k}, t_{0}\right)$ is the creep deformation of the concrete at time $t$ due to the stress $\sigma_{c}\left(t_{0}\right)(\mathrm{MPa})$ acting from time $t_{0}$ to time $t ; \varepsilon_{\mathrm{e}}\left(\mathrm{t}_{0}\right)$ is the instantaneous strain of the concrete at the time of loading, which is the ratio of the stress $\sigma_{c}\left(t_{0}\right)(\mathrm{MPa})$ over the elastic modulus $\mathrm{E}_{\mathrm{c}}\left(\mathrm{t}_{0}\right)(\mathrm{MPa}) ; \mathrm{J}\left(\mathrm{t}_{\mathrm{k}}, \mathrm{t}_{0}\right)$ is defined as the creep function, and $\varphi\left(\mathrm{t}_{\mathrm{k}}, \mathrm{t}_{0}\right)$ is the creep coefficient.

Predicting time-dependent elastic modulus. For control concrete (no supplementary cementitious materials), $\mathrm{E}_{\mathrm{c}}(\mathrm{t})$, can be estimated based on the elastic modulus of concrete at 28 days, $E_{\mathrm{cm}}$ :

$$
E_{\mathrm{c}}(t)=\beta_{E}(t) E_{\mathrm{cm}}=\left\{\exp \left[s\left(1-\sqrt{\frac{28}{t}}\right)\right]\right\}^{0.3} E_{\mathrm{cm}}
$$

Where $\beta_{\mathrm{E}}(\mathrm{t})$ is a coefficient that depends on the age of the concrete, and $s$ depends on the type of cement. The applicability of this equation to SCM concrete was evaluated using data sets from the literature. Figure 1a shows the relationship between the calculated and measured elastic modulus using Eqn. (4). Large variation is seen with many data points exceeding a $20 \%$ threshold.

Equation (5) was modified to incorporate the effects of the SCMs on the time-dependent elastic modulus by considering the composition of the binder. The pozzolanic reaction, which is the dominant chemical reaction for SCMs, takes place after calcium hydroxide is produced by the hydration of Portland cement. Previous research shows that the rate of the pozzolanic reaction is correlated with the ratio of the weights 
of calcium oxide, $\mathrm{CaO}(C)$, to silicon dioxide, $\mathrm{SiO}_{2}(S)$ plus aluminum oxide, $\mathrm{Al}_{2} \mathrm{O}_{3}(A)$; this ratio is often expressed as $C /(S+A)$ (Hannesson et al. 2012; Kuder et al. 2012). The EC2 equation (Eqn. (4)) was modified to improve the estimated elastic modulus for SCM concrete, as following:

$$
E_{\mathrm{c}}(t)=\beta_{E}(t) E_{\mathrm{cm}}=\left\{\exp \left[s\left(1-\sqrt{\frac{28}{t}}\right)\left(-1.60 \frac{C}{S+A}+5.26\right)\right]\right\}^{0.3} E_{\mathrm{cm}}
$$

Figure $1 \mathrm{~b}$ compares the calculated versus measured elastic modulus using Eqn. 5. The results show that the proposed equation reduces the uncertainty in the elastic modulus predictions relative to Eqn. 4. The mean value of the predicted results using Eqn. 5 to the measured values is 0.99 and the coefficient of variation on this is 0.14 .

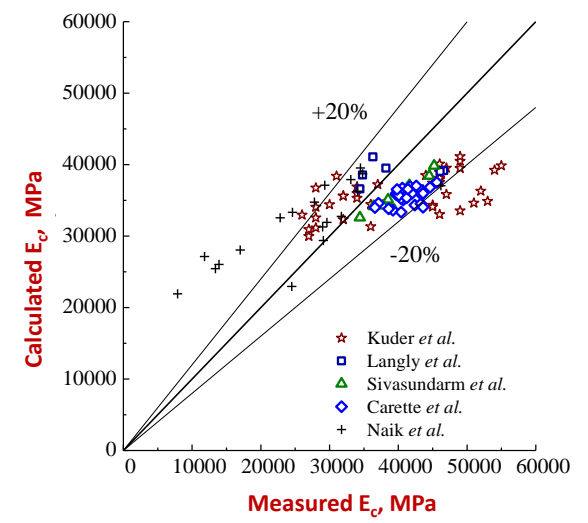

(a)

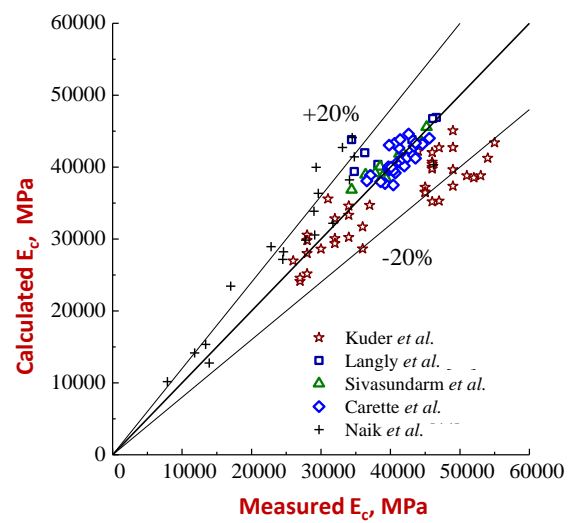

(b)

Figure 1. Calculated Versus Measured Elastic Modulus, Ec, at Different Ages for (a) EC2 Model Using Eqn. (4) and (b) Modified Eqn. (5)

Predicting time-dependent compressive strength. The EC2 equation predicts compressive strength as a function of time, $\mathrm{fc}(\mathrm{t})$, for control concrete.

$$
f_{\mathrm{c}}(t)=\beta_{\mathrm{cc}}(t) f_{\mathrm{cm}}=\exp \left[s\left(1-\sqrt{\frac{28}{t}}\right)\right] f_{\mathrm{cm}}
$$

Where $\beta_{\mathrm{cc}}(\mathrm{t})$ defines strength development with age in days and $f_{\mathrm{cm}}$ is the 28 -day strength. This equation was evaluated for application to SCM concrete using data from previous tests (Langley et al. 1989; Sivasundaram et al. 1991; Carette et al. 1993) with concrete that has a binary mix of cement and fly ash with replacement levels up to $58 \%$ or cement and slag with replacement levels up to $68 \%$. Figure 2a shows the relationship between the calculated and measured compressive strength using Eqn (6). Large variations are seen.

Correlation between development of compressive strength and $\mathrm{C} /(\mathrm{S}+\mathrm{A})$ was investigated. It was observed that $\beta_{\mathrm{cc}}(\mathrm{t})$ decreases with the increasing $\mathrm{C} /(\mathrm{S}+\mathrm{A})$ for concrete less than 28 days old and increases with increasing $\mathrm{C} /(\mathrm{S}+\mathrm{A})$ for concrete greater than 28 days old. The EC2 expression was, therefore, modified:

$$
f_{\mathrm{c}}(t)=\beta_{\mathrm{cc}}(t) f_{\mathrm{cm}}=\exp \left[s\left(1-\sqrt{\frac{28}{t}}\right) \beta_{\mathrm{cc}}\left(\frac{C}{S+A}\right)\right] f_{\mathrm{cm}}
$$




$$
\beta_{\mathrm{cc}}\left(\frac{C}{S+A}\right)= \begin{cases}-0.38 \frac{C}{S+A}+2.12 & t<28 \text { days } \\ -1.15 \frac{C}{S+A}+3.70 & t>28 \text { days }\end{cases}
$$

The accuracy of the proposed equations were evaluated using data from Kuder et al. (Kuder et al. 2012) and Hannesson et al. (Hannesson et al. 2012); these data were not used in the development of the equation. In these studies, binary mixes had replacement levels of fly ash or slag ranging from $20 \%$ to $100 \%$ and the ternary mixes had the replacement percentages of fly ash and slag varying from $60 \%$ to $90 \%$. Concrete compressive strength was determined from 7 to 168 days. Figure $2 \mathrm{~b}$ presents concrete compressive strength calculated using Eqns. (7) and (8) versus the measured strength. The mean value of the predicted results divided by the measured is 1.00 and the coefficient of variation on this is 0.15 . The results show that using Eqns. (7) and (8) provide good estimate of the strength of concrete for a wider range of cement replacement levels with SCMs.

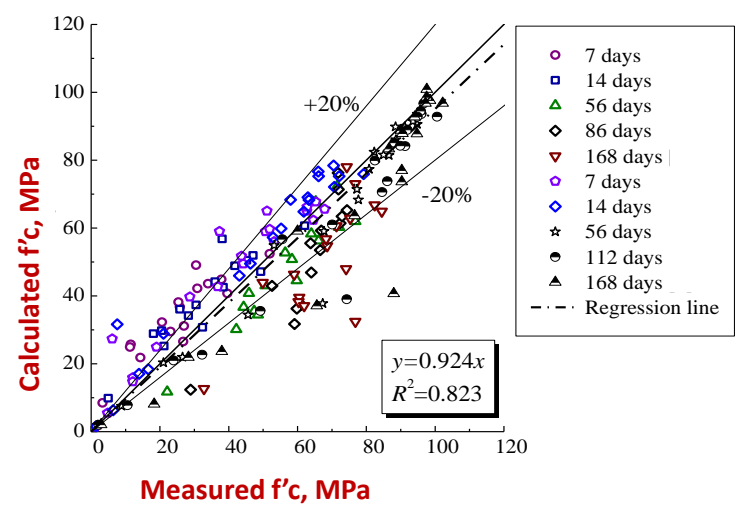

(a)

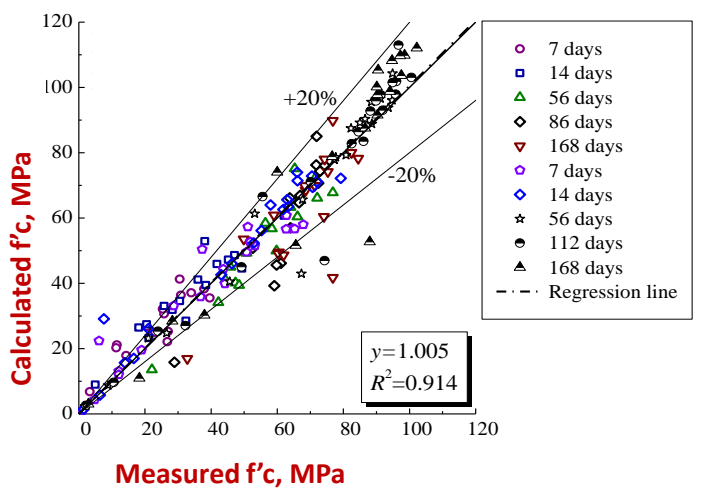

(b)

Figure 2. Calculated Versus Measured Compressive Strength, $f_{c}$, at Different Ages for (a) EC2 Model using Eqn. (6) and (b) Modified Eqns. (7) and (8)

Predicting time-dependent creep behavior. The EC2 model was evaluated using creep data for control concrete (Portland cement only) and concrete with SCMs (Ghosh \& Timusk 1981; Carette et al. 1993; Sivasundaram et al. 1991; Chern \& Chan 1989; Tikalsky et al. 1988; Alexander 1994; Qin et al. 2002; Zhao et al. 2005; Zhao et al. 2009). For studies that did not report the elastic modulus, the modulus was estimated based on $f_{\mathrm{cm}}$ predicted using design expressions from the EC2 model. The experimentally studied variables include: sealed and unsealed curing conditions, compressive strength (15 to $64 \mathrm{MPa}$ ), age at first loading $\left(t_{0}\right)$ (7 to 90 days), and initial stress levels $\left(n_{\mathrm{c}}\right)(0.20-0.40)$. The benchmarking tests include 69 specimens with SCMS with replacement ratios of fly ash (Class C or F) ranging from $12 \%$ to $58 \%$, slag varying between $4.5 \%$ and $68 \%$, and binary replacement (fly ash plus slag) up to $50 \%$

Figure 3 presents the calculated (using EC2) versus measured creep for these data. The comparison suggests that the EC2 model is capable of estimating the creep for control concrete (Figure 3a), but that it tends to overestimate the creep deformation of concrete with SCMs since over $60 \%$ of the calculated values exceed the $30 \%$ limit (Figure 3b). Since the EC2 model does not predict well the creep behavior of SCM concrete; an investigation was undertaken to improve the model. The authors found that $\mathrm{C} /(\mathrm{S}+\mathrm{A})$ and water/binder ratio are indicators for the creep coefficient of SCM concrete. Thus, the relationships between the ratio $\phi_{\mathrm{tes}} / \phi_{\mathrm{EC} 2}$ to the total $C /(S+A)$ ratio in the binder and the $w / b$ ratio in the literature were used to modify the expression of creep coefficient. 


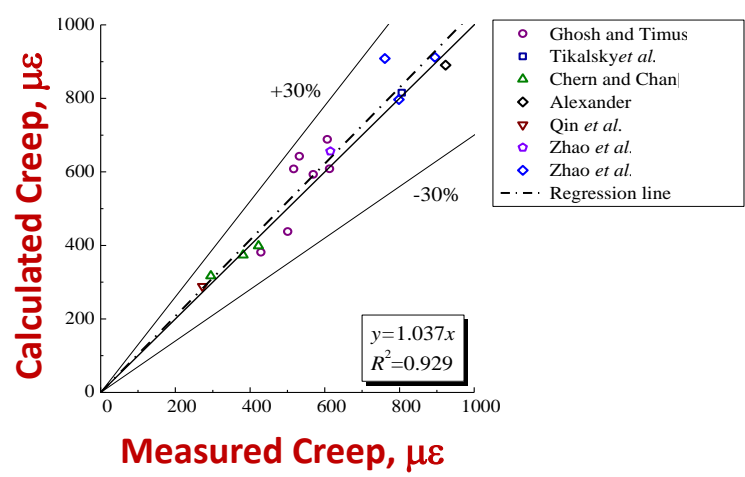

(a)

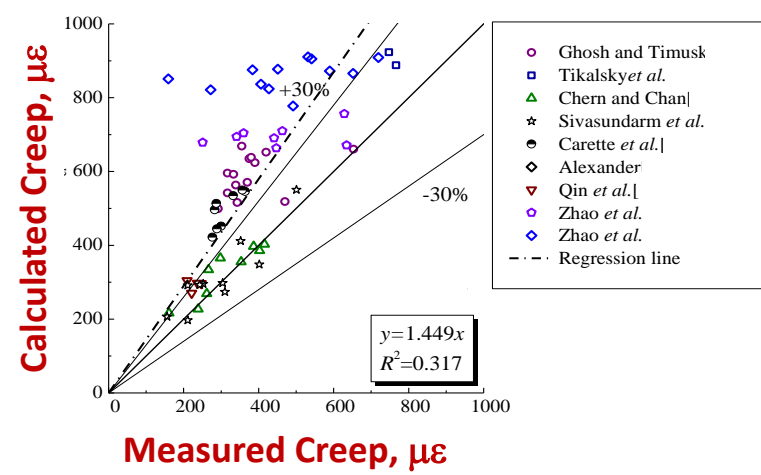

(b)

Figure 3. Calculated Versus Measured Creep at Different Ages for (a) Control Concrete (Portland Cement Only) and (b) Concrete Containing Supplementary Cementitious Materials

The following proposed creep coefficient introduces factors to account for the influences of chemical composition and water-to-binder ratio on the creep behavior of SCM concrete:

$$
\begin{aligned}
& \varphi\left(t, t_{0}\right)=\varphi_{\mathrm{RH}} \beta\left(f_{\mathrm{cm}}\right) \beta\left(t_{0}\right) \beta\left(\frac{C}{S+A}\right) \beta\left(\frac{w}{b}\right) \beta\left(t, t_{0}\right) \\
& \beta\left(\frac{C}{S+A}\right)=0.17 \frac{C}{S+A}+0.87 \\
& \beta\left(\frac{w}{b}\right)=0.74 \frac{w}{b}+0.37
\end{aligned}
$$

The adaptability of the proposed creep model to predict the creep of the control and SCM concrete was evaluated using prior test results of the authors in which ternary SCC mixes were evaluated with $90 \%$ cement replacement (Kuder et al. 2012). Figures 4 and 5 present these data. It is worth noting that the proposed model works well in predicting the creep response of the concrete ternary blends with high volumes of SCMs for a cement replacement ratio of $90 \%$ except for the sealed specimen SCM28. This outlier may be attributed to the substantial variability in data between 40 and 60 days. Overall agreement is good with a mean value of the predicted results divided by the measured is 0.95 and the coefficient of variation on this is 0.08 .

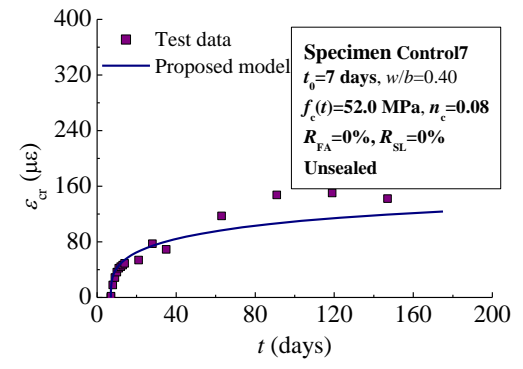

(a)

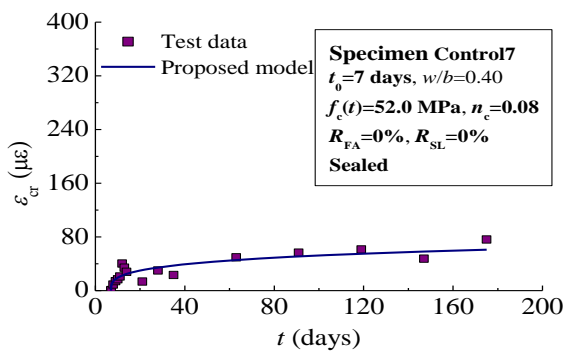

(b)

Figure 4. Creep Versus Time Using Proposed Model for Control Concrete (Portland Cement Only): (a) Unsealed and (b) Sealed 

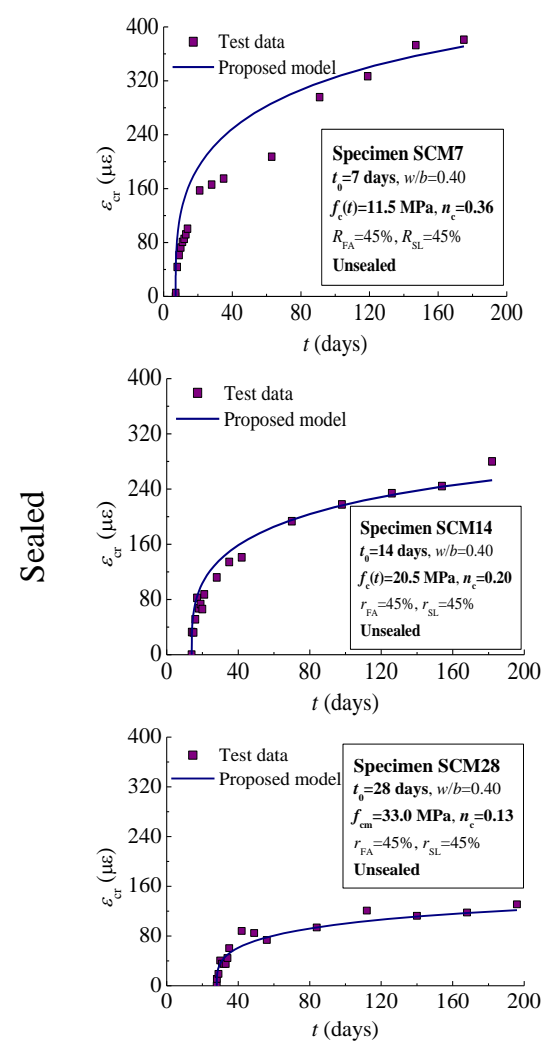
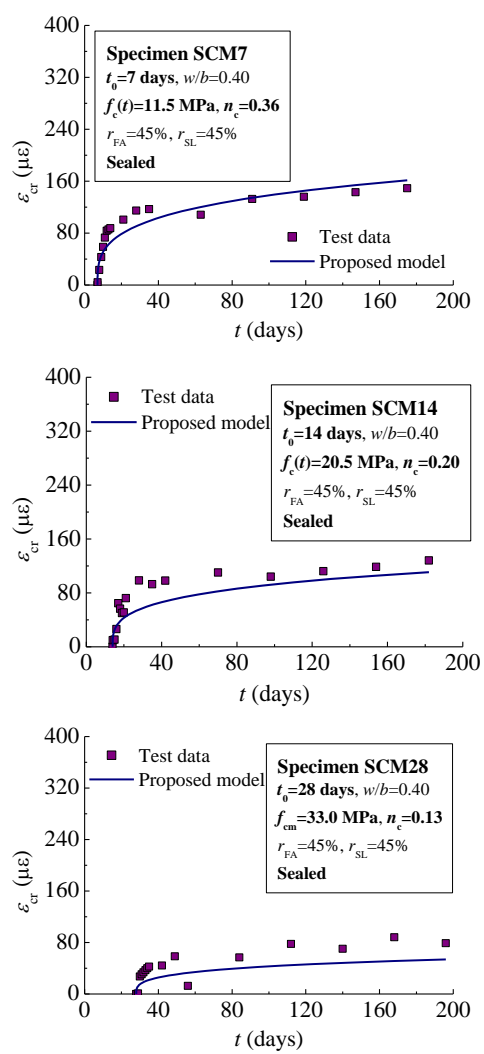

Figure 5. Creep Versus Time Using Proposed Model for High Supplementary Cementitious Material Concrete

\section{VALIDATION AND SIMULATION OF CREEP OF CFT'S WITH SCM CONCRETE}

The long-term behavior of two large-scale CFT-to-foundation specimens with SCMs was evaluated (Lehman et al. 2015). Figure 6 depicts the corresponding experimental setups for the specimens with spirally welded tubes of $508 \mathrm{~mm}$ in diameter (D) and $6.4 \mathrm{~mm}$ in thickness ( $\mathrm{t}$ ) with a $\mathrm{D} / \mathrm{t}$ ratio of 80 . Two concrete mixes were employed: a ternary blend of cement, fly ash and slag with cement replacement ratio of $80 \%$ and binary blends with cement and slag with cement replacement ratio of $35 \%$ were used for the concrete fill in specimens CFT-1 and CFT-2, respectively. The specimens were loaded at 14 days for a duration of 126 days.

A cross-sectional analysis was used to simulate the creep response. The modeling approach assumes perfect bond because prior study by the authors shows that bond capacity is developed within a length of $\mathrm{D} / 2$ (Roeder et al. 1999). The constitutive models included steel, the previously presented concrete strength and stiffness expressions, and the creep of CFTs to determine the time-dependent stresses and strains. The creep of the SCM concrete core was approximated using the integral-type creep law (Chiorino et al. 1984) with a step-by-step procedure which subdivides the time domain t into discrete times (Geng et al. n.d.; Geng et al. 2012). The time-dependent behavior of CFTs included basic creep and autogenous shrinkage in the concrete core; other sources of shrinkage were not included due to the sealed condition by the outer steel tube. 

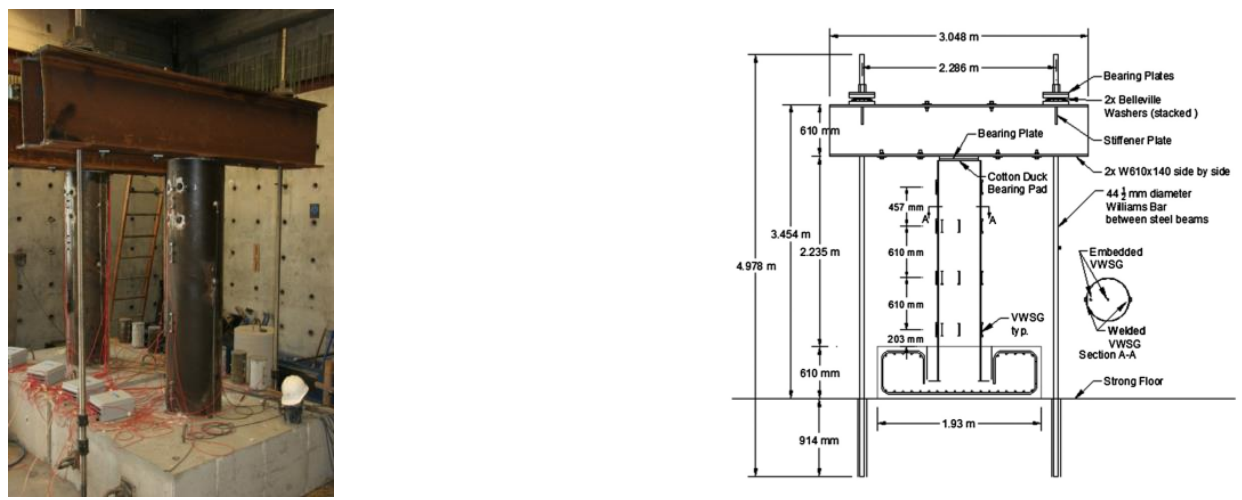

Figure 6. Large-Scale CFTs Sustained Loading Experimental Test Setup

Figure 7 shows the creep strain for the CFT-1 and CFT-2 specimens. The creep strains were low for both concrete types, although the initial concrete strain in the CFT with high-volume SCM was larger. The authors also found that the steel strains were negligible for both specimens. The proposed models were used to predict the strain-time response curve.

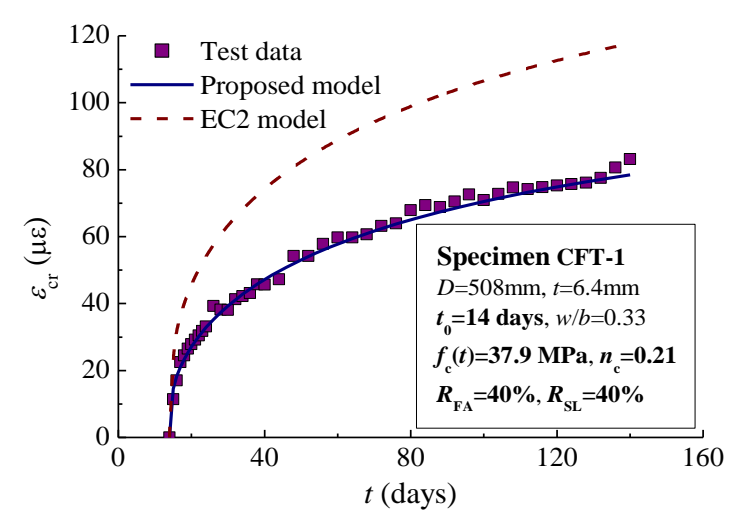

(a)

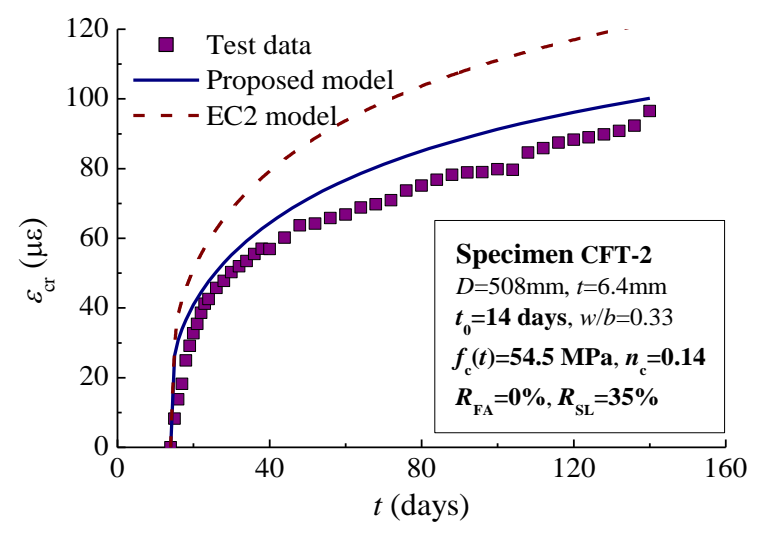

(b)

\section{Figure 7. Calculated and Measured Creep response for Large-Scale CFTs with SCMs Under}

Sustained by Lehman et al. ((Lehman et al. 2015)) using Proposed Model

The comparison between the test results and the predictions are presented in Figure 7. The predicted and simulated results compare well with the scatter of 5\% or less. In comparison, the EC2 model (implemented without SCM modification) overestimated the creep response by $42 \%$ and $27 \%$ for specimen CFT-1 (ternary blend SCM concrete) and CFT-2 (binary blend SCM concrete), respectively. Therefore, the proposed model can be applied to predict the creep behavior of CFTs with high-volumes of fly ash and slag with cement replacement ratio up to $80 \%$.

\section{CONCLUSION}

The aim of this research is to develop a model capable of adequately predicting the creep behavior of concrete with high volumes of fly ash and slag. Accurate predictions of the time-dependent elastic modulus 
and compressive strength of SCM concrete are needed to understand and model creep of SCM concretes. To do so, the research developed and verified time-dependent relationships to modify the EC2 equations. The modifications were based on the available SCM concrete experimental results in the literature.

Comparison of the experimental results and basic EC2 models show that the binder ratio $C /(S+A)$ affects the rate of development of the elastic modulus and compressive strength. Therefore, the binder ratio $C /(S+A)$ was used to modify to the available model equations for all types of the SCMs. Using these relationships, the creep behavior of SCM concrete was investigated. The results show that the EC2 model usually overestimates creep deformations and creep coefficients of SCM concrete. It was postulated that this occurs, because some of SCM remains unreacted and therefore functions as inert filler providing higher resistance to creep than conventional creep. The modification used the $C /(S+A)$ binder ratio and $w / b$ ratio as additional input parameters. These modified equations are in good agreement with the experimental values.

Finally the models were used to evaluate understand the impact of creep of CFTs with SCM-concrete. The numerical model accurately predicted the creep of CFTs with fly ash and slag, with replacement level as high as $80 \%$.

\section{REFERENCES}

Alexander, M., 1994. Deformation properties of blended cement concretes containing blastfurnace slag and condensed silica fume. Advances in Cement Research, 6(22), pp.73-81.

Bazant, Z. \& Baweja, S., 2000. Creep and shrinkage prediction model for analysis and design of concrete structures: model B3. In Adam Neville Symposium: creep and shrinkage-structural design effects. pp. $1-83$.

Carette, G. et al., 1993. Mechanical properties of concrete incorporating high volumes of fly ash. ACI Materials Journal, 90(6), pp.535-544.

Castel, A. et al., Creep and drying shrinkage of a blended slag and low calcium fly ash geopolymer Concrete. Materials and Structures.

Cembureau, 2013. Cembureau Activity Report, Brussels: CEN.

Chern, J.-C. \& Chan, Y.-W., 1989. Deformations of concretes made with blast-furnace slag cement and ordinary Portland cement. ACI Materials Journal, 86(4), pp.372-382.

Chiorino, M. et al., 1984. CEB Design Manual on Structural Effects of Time-Dependent Behaviour of Concrete, Saint-Sphorin (Switzerland).

European Committee for Standardization (CEN) EN, 1992. Eurocode 2: Design of concrete structures Part 1-1: General rules and rules for buildings, Brussels: CEN.

Geng, Y. et al., 2012. Time-Dependent Behaviour of Concrete-Filled Steel Tubular Columns: Analytical and Comparative STudy. Magazine of Concrete Research, 64, pp.55-69.

Geng, Y., Wang, Y. \& Chen, J., Time-Dependent Behacvior of Recycled Aggregate Concrete-Filled Steel Tubular Columns. Joruanl of Structural Engineering.

Ghosh, R. \& Timusk, J., 1981. Creep of fly ash concrete. ACI Journal Proceedings, (325), pp.351-357. Available at: http://www.concrete.org/Publications/InternationalConcreteAbstractsPortal.aspx?m=details\&i=10519. 
Hannesson, G. et al., 2012. The influence of high volume of fly ash and slag on the compressive strength of self-consolidating concrete. Construction and Building Materials, 30, pp.161-168. Available at: http://www.sciencedirect.com/science/article/pii/S0950061811006775.

Holger, L.K. et al., 2012. Selecting Creep Models Using Bayesian Methods. Materials and Structures, 45(10), pp.1513-1533.

Kuder, K. et al., 2012. Mechanical properties of self consolidating concrete blended with high volumes of fly ash and slag. Construction and Building Materials, 34, pp.285-295. Available at: http://dx.doi.org/10.1016/j.conbuildmat.2012.02.034.

Langley, W., Carette, G. \& Malhotra, V., 1989. Structural concrete incorporating high volumes of ASTM Class F fly ash. ACI Materials Journal, 86(5), pp.507-514.

Lehman, D. et al., 2015. Circular Concrete-Filled Tubes for Improved Sustainability and Seismic Resilience. Journal of Structural Engineering, 141(3).

Lehman, D. \& Roeder, C., 2012. Foundation Connections of Circular Concrete-Filled Tubes. Journal of Constructional Steel Research, 78, pp.212-225.

Li, J., 2001. A study on creep and drying shrinkage of high performance concrete. Cement and Concrete Research, 31(8), pp.1203-1206.

Lohtia, R., Nautiyal, B. \& Jain, O., 1976. Creep of fly ash concrete. In ACI Proceedings. pp. 469-472.

Mehta, P.K., 2009. Global Concrete Industry Sustainability: Tools for Moving Forward to Cut Carbon Emissions. Concrete international, 31(2), pp.45-48.

Moon, J. et al., 2013. Strength of Circular Concrete-Filled Tubes with and without Internal Reinforcement Under Combined Loading. Journal of Structural Engineering, 139(2).

Nasser, A. \& AI-Manaseer, A., 1986. Creep of concrete containing fly ash and superplasticizer at different stress/strength ratios. In ACI Journal Proceedings1. pp. 668-673.

Nasser, K.W., 1987. Creep of Concrete Containing Fly Ash and Superplasticizer at Different Stress / Strength Ratios. , (83), pp.668-673.

Qin, H., Pan, G. \& Sun, W., 2002. Study on the deformation properties of the high performance concrete with fly ash used in bridge. Journal Southeast University, 32, pp.779-782.

Roeder, C., Cameron, B. \& Brown, C., 1999. Composite Action in Concrete Filled Tubes. Journal of Structural Engineering, 125(5), pp.477-484.

Roeder, C., Lehman, D. \& Bishop, E., 2010. Strength and Stiffness of Circular Concrete-Filled Tubes. Journal of Structural Engineering, 136(12), pp.1545-1553.

Sivasundaram, V., Carette, G. \& Malhotra, V., 1991. Mechanical properties, creep, and resistance to diffusion of chloride ions of concretes incorporating high volumes of ASTM Class F fly ashes from seven different sources. ACI Materials Journal, 88(4), pp.407-416.

Tikalsky, P.J., Carrasquillo, P. \& Carrasquillo, R., 1988. Strength and durability considerations affecting mix proportioning of concrete containing fly ash. ACI Materials Journal, 85(6), pp.505-511.

Wang, J., Xu, J. \& Gao, D., Numerical relationship between creep deformation coefficients of prestressed concrete beams. Materials and Structures.

Zhao, Q., Sun, W. \& Miao, C., 2009. Effect and mechanism of interaction between fly ash proportion and water-binder ratio on the creep characteristics of high performance concrete. China Civil Engineering Journal, 42(12), pp.76-82. 
Zhao, Q.-X. et al., 2005. Creep character of high performance concrete with ground granulated blast furnace slag and fly ash. Journal of Wuhan University of Technology, 27(11), pp.35-38. 